\title{
Effect of pre-treatment procedure on micropore system characteristics of subbituminous coal
}

\author{
T. Zelenka \\ Department of Chemistry, University of Ostrava, Czech Republic
}

\begin{abstract}
Various pre-treatment procedures like hot oven drying under and without vacuum, purging with an inert gas at elevated temperatures, lyophilisation and long-term drying in a desiccator were applied on a sample of a subbituminous coal. Variously dried samples with known residual moisture contents were interpreted according to the microporous textural parameters. Adsorption isotherms of $\mathrm{CO}_{2}$ at $30^{\circ} \mathrm{C}$ were determined using a volumetric sorption analyser. Adsorption data were evaluated according to Dubinin-Radushkevich and Medek's equation in order to determine micropores' volume and micropores' surface and modus of the micropores' radii.

It was found that the drying method has an influence on the microporous textural properties. Samples which were not exposed to oxygen during drying (vacuum drying, inert gas purging) have better micropore characteristics; likely due to the lower contents of the residual moisture in the order of a few tenths wt.\%. If a sample is exposed to an oxidizing atmosphere at a comparable temperature and drying time, the reduction of the textural parameters was observed. It may be explained by a higher residual moisture content of this sample (1.4 wt. \%). The effect of the drying temperature has not been clearly proven despite the fact that mean $S_{m i}$ and $V_{m i}$ parameters have an increasing tendency with a decreasing drying temperature. It was also found that 2 hours is an effective time for the vacuum drying process at $60^{\circ} \mathrm{C}$; even despite the difference in residual moisture contents of these samples.
\end{abstract}

Keywords: subbituminous coal, pre-treatment procedure, surface area, micropores. 


\section{Introduction}

Subbituminous coal is considered to be a naturally microporous carbon material which contains a significant amount of moisture in its structure [1, 2]. Studies concerning the influence of moisture on the $\mathrm{CO}_{2}$ sorption capacity generally state that the presence of moisture leads to a decrease in sorption capacity [3-5]. For instance, Švábová et al. [6] examined the effect of the moisture on three coal samples which differ in the degree of coalification. They found out that in all of the cases, the moisturized coal showed lower sorption capacity of the carbon dioxide than the dry coal.

It is obvious that proper moisture removal from the structure of the coal is very important for achieving the maximum sorption capacity due to the good accessibility of adsorbed gas. Brennan et al. [7] found out that the mechanism that leads to a reduction in $\mathrm{CO}_{2}$ adsorption is the formation of clusters which can effectively block the entire pore space. Day et al. [3] examined that in low rank coals, moisture had a greater effect on the sorption capacity than in high rank coals. Probably because of the greater proportion of polar sites which are preferentially occupied by water at the expense of $\mathrm{CO}_{2}$ and also $\mathrm{CH}_{4}$.

Moisture content of the coal is connected with oxygen containing functional groups. These functional groups act as primary adsorption centres [6]. At any time during the pre-treatment process (including not only the drying procedure, but also storing of the coal) when the sample is in contact with oxygen, physical and chemical changes can occur $[1,2]$. This natural process is known as lowtemperature oxidation of the coal and it progresses at a normal temperature up to $100^{\circ} \mathrm{C}$ [2]. Some authors consider higher temperatures up to $200^{\circ} \mathrm{C}[2,8]$. The low-temperature oxidation leads to formation and/or elimination of polar functional groups, especially hydroxyl groups but also carboxyl, methoxyl and carbonyl groups $[1,2]$. There is an expectation that the presence of a nonoxidizing atmosphere during the pre-treating process, such as vacuum or inert, will repress oxidation of the sample. However, the oxidation process of the coal is expected during drying in an oxidizing atmosphere [2].

Various drying processes have been developed since the 1920s. Among them were the superheated and pressurized steam drying, hot and supercritical water drying and hydro thermal-mechanical compression drying processes [9, 10]. On the other hand, the use of high-pressure equipment provides crucial economical disadvantages in the process.

The micropore properties of coals with respect to its moisture content have already been studied $[3,6]$. Nevertheless, the influence of various pre-treatment methods according to assessment of microporous properties of (subbituminous) coal has not been published yet.

For this purpose, various pre-treatment procedures were chosen and applied to the samples of the subbituminous coal. The aim of this paper was to describe a different final state of the subbituminous coal obtained after various pretreatment procedures. This final state has been characterized with respect to their microporous textural parameters. 


\section{Experimental part}

\subsection{Sample}

A sample of subbituminous coal taken from the Czech part of the North Bohemian Coal Basin was chosen for the study. The sample was crushed in a ball mill to obtain the grain size of $0.06-0.15 \mathrm{~mm}$. The thus obtained material was stored in closable plastic container in a refrigerator at $3{ }^{\circ} \mathrm{C}$. The basic quantitative parameters of the coal are given in table 1 .

Table 1: $\quad$ Basic characteristics of the studied coal sample (wt.\%).

\begin{tabular}{|c|c|c|c|c|c|c|}
\hline \multicolumn{7}{|c|}{ Ultimate and proximate analysis } \\
\hline$C^{\text {daf }}$ & $H^{\text {daf }}$ & $N^{\text {daf }}$ & $O_{\text {dif }}^{\text {daf }}$ & $S_{t}^{d}$ & $A^{d}$ & $W_{t}$ \\
\hline 74.4 & 6.5 & 1.0 & 16.8 & 1.3 & 8.0 & 18.0 \\
\hline \multicolumn{7}{|c|}{ Ash analysis } \\
\hline $\mathrm{CaO}$ & $\mathrm{SiO}_{2}$ & $\mathrm{Al}_{2} \mathrm{O}_{3}$ & $\mathrm{Fe}_{2} \mathrm{O}_{3}$ & $\mathrm{MnO}$ & $\mathrm{MgO}$ & $\mathrm{TiO}_{2}$ \\
\hline 4.0 & 51.2 & 27.5 & 6.4 & 0.01 & 0.8 & 3.2 \\
\hline
\end{tabular}

$A$ - ash, $d$ - dry basic, daf - dry and ash-free basic, $t$ - total, dif - by difference, $W$ - moisture content.

\subsection{Pre-treatment methods}

Five pre-treatment procedures were studied on this sample with regard to its textural parameters.

(i) Hot oven drying under vacuum is intended to prevent oxidation of the sample. The effect of the various drying temperatures and time was investigated. Monitoring the impact of the vacuum drying at various elevated temperatures $\left(60,80\right.$ and $\left.105^{\circ} \mathrm{C}\right)$ was carried out at a constant drying time of 5 hours. In the case of different pre-treatment times under vacuum (2, 5 and 8 hours), the constant drying temperature of $60^{\circ} \mathrm{C}$ was chosen. These experiments were performed in the hot oven ( $\mathrm{mfr}$. Javoz) using the vacuum pump ( $\mathrm{mfr}$. Laboratorní prístroje Praha; limit of pressure around $100 \mathrm{~Pa}$ ).

(ii) Purging of the sample at elevated temperature with an inert nitrogen atmosphere is another method that protects the adsorbent to its oxidation. This procedure was carried out in the same (above mentioned) oven at $60^{\circ} \mathrm{C}$ for 5 hours at nitrogen flow $50 \mathrm{~cm}^{3} \mathrm{~min}^{-1}$. The sample was placed on the bottom of the glass U-tube during the purging procedure.

(iii) Another vacuum drying procedure used to prevent oxidation of the adsorbent is lyophilisation (mfr. Labconco), which unlike the method (i) takes place at a low temperature. This non-evaporate method differs from others in the context of the phase transition (sublimation occurs). Before the lyophilisation process, the sample in a glass lyophilisation flask was frozen by liquid nitrogen. The actual sample temperature during this procedure could not be monitored, but the temperature in the condenser was $-87^{\circ} \mathrm{C}$ during the entire process. This type of pre-treatment procedure lasted for 70 hours at pressure $50 \mathrm{~Pa}$. 
(iv) Convex hot air oven pre-treating is a process performed under elevated temperature. It is one of two methods in which oxidation is to be expected. The pre-treatment process was carried out at $60^{\circ} \mathrm{C}$ for 5 hours (mfr. Chirana).

(v) Finally, the ambient temperature (at $\sim 25^{\circ} \mathrm{C}$ ) and ambient pressure drying process took place in a desiccator with a silica gel. The sample was exposed to air on a long-term basis (216 hours) therefore oxidation of the coal sample is to be expected.

The effects of the pre-treatment temperature and time as well as the effect of the residual moisture content were evaluated with regard to all the abovementioned pre-treated methods. All the pre-treatment parameters are presented in table 2 .

Table 2: $\quad$ Parameters of the pre-treatment procedures.

\begin{tabular}{|c|c|c|c|}
\hline Sample & $\begin{array}{l}\text { Pre-treatment } \\
\text { procedure }\end{array}$ & $\begin{array}{c}\text { Temperature } \\
{\left[{ }^{\circ} \mathrm{C}\right]}\end{array}$ & $\begin{array}{l}\text { Time } \\
\text { [hour] }\end{array}$ \\
\hline 1 & \multirow{5}{*}{ vacuum } & 60 & \multirow{3}{*}{5} \\
\hline 2 & & 80 & \\
\hline 3 & & 105 & \\
\hline 4 & & \multirow{4}{*}{60} & 2 \\
\hline 5 & & & 8 \\
\hline 6 & inert gas & & \multirow{2}{*}{5} \\
\hline 7 & hot air oven & & \\
\hline 8 & lyophilisation & -87 & 70 \\
\hline 9 & desiccator & $\sim 25$ & 216 \\
\hline
\end{tabular}

The treated sample was separated into two portions. The first portion was used for carbon dioxide adsorption analysis.

The second part of the sample was dried at $105^{\circ} \mathrm{C}$ in hot air oven $(\mathrm{mfr}$. Chirana) to constant weight in order to determine the amount of the residual moisture according to the norms ČSN ISO 5069-1 and 5069-2. There is an expectation that the residual moisture content will vary depending on the used drying method, which should be reflected in the textural parameters of the sample.

\subsection{Volumetric sorption analysis}

Carbon dioxide isotherms were measured by means of a Setaram PCTPro E\&E volumetric analyser. All the measurements were carried out at $30^{\circ} \mathrm{C}$ and over the relative pressure range up to $0.014 p / p_{s}(0-1$ bar of absolute pressure expression). The weight of the sample was $0.7 \mathrm{~g}$. A dead volume of the sample cell was measured first by the helium expansion technique. Hy-Data E\&E software (Setaram) was used to specify different adsorption parameters. In the course of the sorption process, the sample temperature was automatically controlled. 


\subsection{Interpretation of carbon dioxide isotherms}

Obtained adsorption data were interpreted according to Dubinin theory, based on the effect of overlapping adsorption potentials of opposite walls in micropores. Here, an amplified adsorption field is formed where volume filling occurs at pressures much lower than the saturation pressure and the rest of the surface is negligibly covered [11-13]. This sorption mechanism is described by the following Dubinin-Radushkevich (DR) eqn (1):

$$
\ln V=\ln V_{0}-\frac{R^{2} T^{2}}{E^{2}} \ln ^{2}\left(\frac{p_{s}}{p}\right)
$$

where $V$ is the volume of micropores occupied by adsorbed carbon dioxide at equilibrium pressure $p, V_{0}$ is a constant representing limiting (total) volume of micropores (corresponds with $V_{m i}$ ), $R$ is the gas constant, $E$ is the characteristic energy and $p_{s}$ is the saturated pressure of $\mathrm{CO}_{2}$ vapour at temperature $T$.

This DR equation manifests a linear plot in coordinates $\ln V$ versus $\ln ^{2}\left(p_{s} / p\right)$ (see fig. 1). From the $\ln V$ intercept of the plot, the limiting value of the micropores volume $V_{0}$ was evaluated. In addition, from the slope of the DR plots, characteristic energy $E$ was determined which was further used for calculation of the micropores surface area $S_{m i}$ by means of Medek's eqn (2) [12]:

$$
S_{m i}=1.86 \cdot V_{0} \cdot\left(\frac{E}{k}\right)^{\frac{1}{3}}
$$

where $k$ is the constant characterizing interactions between carbon dioxide and the carbonaceous surface $[11,12,14]$. Values of all necessary parameters applied to evaluate adsorption isotherms of $\mathrm{CO}_{2}$ at $30^{\circ} \mathrm{C}$ according to DR eqn (1) and Medek's eqn (2) are given in table 3.

Table 3: $\quad$ Properties of $\mathrm{CO}_{2}$ at $30^{\circ} \mathrm{C}$.

\begin{tabular}{|l|lr|}
\hline Molar density of a liquid phase & $73.595 \mathrm{~cm}^{3} \mathrm{~mol}^{-1}$ & {$[15]$} \\
\hline Saturated pressure, $p_{s}$ & $72.763 \mathrm{bar}$ & {$[15]$} \\
\hline $\begin{array}{l}\text { Interaction constant with carbonaceous } \\
\text { surface, } k\end{array}$ & $3.145 \mathrm{~kJ} \mathrm{~nm}^{3} \mathrm{~mol}^{-1}$ & {$[11,12,14]$} \\
\hline
\end{tabular}

The distribution curve of micropores was calculated using following eqn (3) on the basis of Medek's equation [12]:

$$
\frac{d V}{d r}=6 \cdot V_{0} \cdot\left(\frac{k}{E}\right)^{2} \cdot r^{-7} \cdot e^{-\left(\frac{k}{E}\right)^{2} \cdot r^{-6}}
$$

The modus of the micropores radii $r_{\text {mode }}$ (eqn (4)) was derived from the micropores size distribution [12]:

$$
r_{\text {mode }}=\left[\left(\frac{6}{7}\right)^{\frac{1}{2}} \cdot \frac{k}{E}\right]^{\frac{1}{3}}
$$




\section{Results and discussion}

\subsection{Error of the measurements}

According to the rectified Dubinin-Radushkevich isotherms and the high determination coefficients $R^{2}$ better than 0.99 , it is obvious that this subbituminous coal sample complies very well with the dependence in the Dubinin coordinates $\ln V$ versus $\ln ^{2}\left(p_{s} / p\right)$ (see fig. 1).

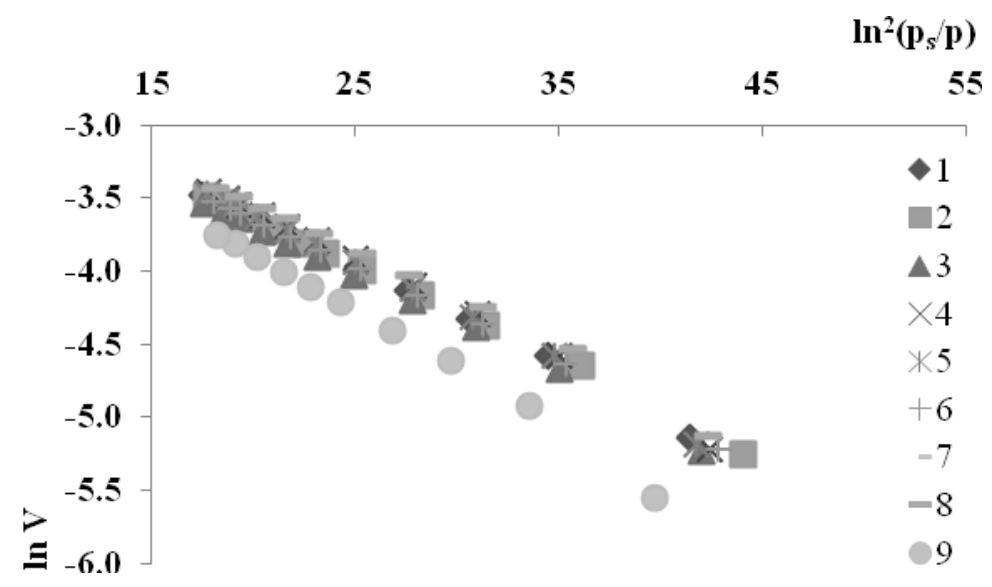

Figure 1: Dubinin-Radushkevich plots of the adsorption data of $\mathrm{CO}_{2}$ at samples of the coal. The numbers correspond to different ways of drying from table 2. All samples exhibit high determination coefficients better than 0.99 .

Each of the nine DR isotherms consisting of 10-12 points were statistically evaluated by linear regressions according to the $95 \%$ confidence intervals.

Table 4 summarizes textural parameters of all the samples. For example, sample 1 exhibits $95 \%$ confidence interval $0.109 \pm 0.009 \mathrm{~cm}^{3} \mathrm{~g}^{-1}$ for the $V_{m i}$ and $294 \pm 26 \mathrm{~m}^{2} \mathrm{~g}^{-1}$ for the $S_{m i}$ as well as $E=9.64 \pm 0.22 \mathrm{~kJ} \mathrm{~mol}^{-1}$. It is obvious that the $95 \%$ confidence intervals of most samples are overlapping. These samples can be considered as equivalent according to the monitored parameters.

\subsection{Effect of the oxidizing atmosphere}

It was found that the pre-treatment process has a significant influence on the final state of the sample. As presented in table 4, there is no pre-treatment procedure which would lead to a completely dry coal sample. However, with regard to the accuracy of the used analytical method of determination of the 
residual moisture content, values $\leq 0.2$ wt. $\%$ can be considered as dry states of the coal samples.

The effect of the oxidizing atmosphere was studied on the samples 1, 6 and 7, which were pre-treated at $60^{\circ} \mathrm{C}$ for 5 hours. The samples 1 and 6 , which were not exposed to the oxidizing processes, were dried under vacuum and purged with an inert gas, respectively.

Table 4: $\quad$ Textural parameters of the microporous subbituminous coal dried by various methods.

\begin{tabular}{|c|c|c|c|c|c|}
\hline & \multicolumn{2}{|c|}{ Dubinin-Radushkevich } & \multicolumn{2}{c|}{ Medek } & \\
\hline Sample & $\begin{array}{c}V_{m i} \\
{\left[\mathrm{~cm}^{3} \mathrm{~g}^{-1}\right]}\end{array}$ & $\begin{array}{c}E \\
{\left[\mathrm{~kJ} \mathrm{~mol}^{-1}\right]}\end{array}$ & $\begin{array}{c}S_{m i} \\
{\left[\mathrm{~m}^{2} \mathrm{~g}^{-1}\right]}\end{array}$ & $\begin{array}{c}r_{\text {mode }} \\
{[\mathrm{nm}]}\end{array}$ & $\begin{array}{c}W_{\text {res }} \\
{[\mathrm{wt.} \%]}\end{array}$ \\
\hline 1 & $0.109 \pm 0.009$ & $9.64 \pm 0.22$ & $294 \pm 26$ & 0.67 & $\leq 0.2$ \\
\hline 2 & $0.099 \pm 0.004$ & $9.83 \pm 0.12$ & $268 \pm 12$ & 0.67 & $\leq 0.2$ \\
\hline 3 & $0.097 \pm 0.006$ & $9.69 \pm 0.17$ & $262 \pm 19$ & 0.67 & $\leq 0.2$ \\
\hline 4 & $0.113 \pm 0.010$ & $9.55 \pm 0.23$ & $303 \pm 30$ & 0.67 & 0.6 \\
\hline 5 & $0.111 \pm 0.009$ & $9.54 \pm 0.22$ & $297 \pm 28$ & 0.67 & $\leq 0.2$ \\
\hline 6 & $0.100 \pm 0.006$ & $9.75 \pm 0.16$ & $272 \pm 17$ & 0.67 & 0.4 \\
\hline 7 & $0.093 \pm 0.007$ & $9.10 \pm 0.15$ & $247 \pm 19$ & 0.68 & 1.4 \\
\hline 8 & $0.115 \pm 0.013$ & $9.66 \pm 0.29$ & $311 \pm 38$ & 0.67 & 0.5 \\
\hline 9 & $0.106 \pm 0.012$ & $8.84 \pm 0.24$ & $278 \pm 35$ & 0.69 & 2.1 \\
\hline
\end{tabular}

$V_{m i}-$ volume of micropores, $E-$ characteristic energy, $S_{m i}$ - surface of micropores, $r_{\text {mode }}-$ modus of micropore radii, $W_{\text {res }}$ - residual moisture content.

On the other hand, drying of the sample 7 was carried out under oxidizing conditions. All the microporous parameters are presented in table 4 and fig. 2 . Note that the $Y$ axis corresponding with the $S_{m i}$ has its minimum at $200 \mathrm{~m}^{2} \mathrm{~g}^{-1}$ and $S_{m i}$ of the samples 1, 6 (and also 7) corresponds with the drying temperature $60^{\circ} \mathrm{C}$ (corresponding points are slightly shifted for readability of the error bars). As can be seen, the mean values of the $95 \%$ confidence intervals of the samples dried at non-oxidizing atmosphere correspond with the micropore surfaces 294 and $272 \mathrm{~m}^{2} \mathrm{~g}^{-1}$. Their micropore volumes are 0.109 and $0.100 \mathrm{~cm}^{3} \mathrm{~g}^{-1}$. In contrast, one air dried sample exhibits $S_{m i} 247 \mathrm{~m}^{2} \mathrm{~g}^{-1}$ and $V_{m i} 0.093 \mathrm{~cm}^{3} \mathrm{~g}^{-1}$.

As expected, the micropore characteristics of the samples which were not exposed to oxygen during drying are better (according to their mean values). This fact may be explained by the presence of the residual moisture, which is higher for the hot air dried sample (1.4 wt. \%). Higher moisture content may also be responsible for lower characteristics energy $9.10 \pm 0.15 \mathrm{~kJ} \mathrm{~mol}^{-1}$ and higher values of the $r_{\text {mode }} 0.68 \mathrm{~nm}$. Samples pre-treated under a non-oxidizing atmosphere exhibit $W_{\text {res }} \leq 0.4$ wt. \%. This is in agreement with the claim of Švábová et al. [6]. They confirmed that drying under oxidizing atmosphere may be a consequence of reduction of the textural parameters because of filling of micropores by moisture likely occurs. However, this claim should relate to only 
samples 1 and 7 because their 95\% confidence intervals (for such statistical evaluation) do not overlap (see fig 2 or table 4).

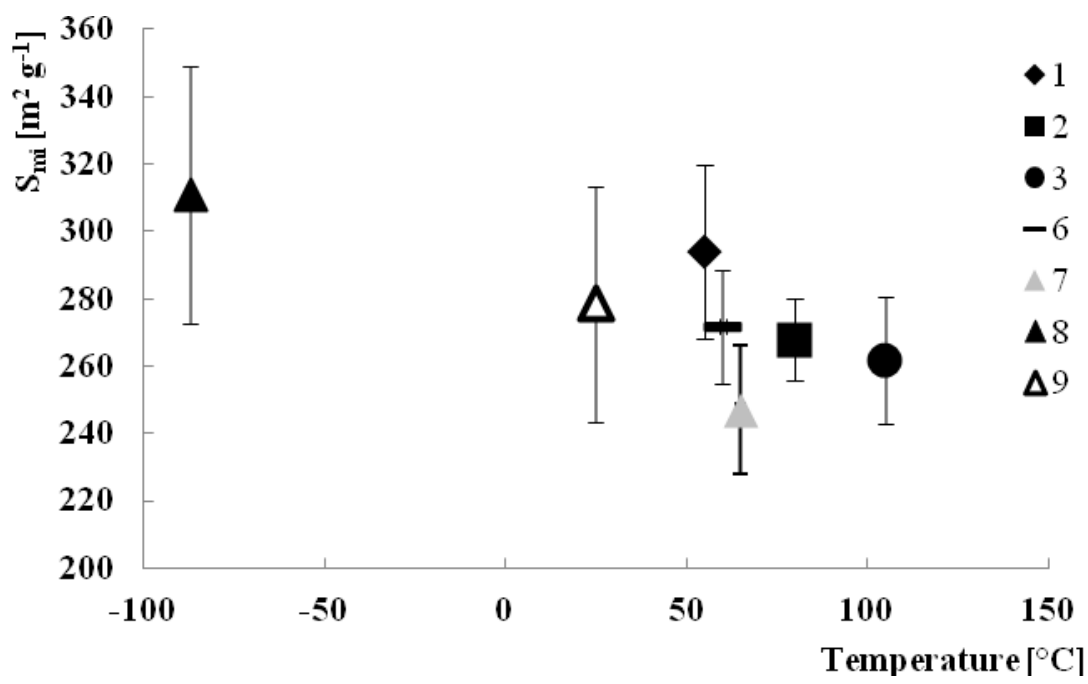

Figure 2: $\quad$ Effect of the drying temperature (across the various pre-treatment methods) on $S_{m i}$. A micropore surface area of the samples 1, 6 and 7 corresponds with the temperature $60^{\circ} \mathrm{C}$. Each error bar represents the error of the measurement.

\subsection{Effect of drying temperature}

In the case of samples which were not exposed to oxidation (specif. 1, 2, 3), the drying process was carried out under vacuum for 5 hours. The effect of temperature drying was monitored at 60,80 and $105^{\circ} \mathrm{C}$.

The micropore parameters $S_{m i}$ and $V_{m i}$ exhibit the range $262-294 \mathrm{~m}^{2} \mathrm{~g}^{-1}$ and $0.097-0.109 \mathrm{~cm}^{3} \mathrm{~g}^{-1}$, respectively (in favour of the sample dried at a lower temperature) and constant modus of micropore radii $0.67 \mathrm{~nm}$. This drying procedure running under non-oxidizing atmosphere, where the oxidation process is repressed, produces basically dry adsorbents $\left(W_{\text {res }} \leq 0.2 \mathrm{wt}\right.$. \%) irrespective of the drying temperature. The effect of the temperature could also be assessed with respect to the sample 8 , which was dried using lyophilisation at low temperature. The oxidizing processes are also repressed according to this method. However, the drying time is far longer ( 70 hours) in comparison with the above discussed samples. As can be seen, the long drying time is not a guarantee of getting a dry sample (residual moisture content was $0.5 \mathrm{wt}$ \%). This drying method performed under $-87^{\circ} \mathrm{C}$ exhibits the same $\left(r_{\text {mode }}=0.67 \mathrm{~nm}\right)$ and slightly higher mean values of the $V_{m i}=0.115 \mathrm{~cm}^{3} \mathrm{~g}^{-1}$ and $S_{m i}=311 \mathrm{~m}^{2} \mathrm{~g}^{-1}$ than samples 1 - 3. It may seem that $S_{m i}$ and $V_{m i}$ have increasing tendency with decreasing drying temperature (from 105 to $-87^{\circ} \mathrm{C}$ ), but all the micropore parameters lie within the $95 \%$ 
confidence interval, consequently this fact cannot be clearly confirmed from these data. The small scatter of values of the $E$ (from 9.64 to $9.83 \mathrm{~kJ} \mathrm{~mol}^{-1}$ ) and constancy of the $r_{\text {mode }}(0.67 \mathrm{~nm})$ indicates the same adsorption potential standpoint of all the samples.

The influence of temperature is also related with the influence of various phase transitions when drying under vacuum. While drying the samples at elevated temperatures leads to removal of moisture through evaporation, in the case of the lyophilisation process the moisture leaves through the sublimation.

Capillary effects are suppressed and destruction of the microporous coal during the lyophilisation procedure should not occur. However, based on established textural parameters, the lyophilisation process did not significantly improve the textural properties of the sample. This is in line with the claim of Evans et al. [16], which found out that collapse of the coal structure through capillary effect is relatively small. Nevertheless, Deevi et al. [17] found out that shrinkage (collapse) of the coal during drying occurs (only) at the level of macropores.

The effect of the temperature of pre-treating in an oxidizing atmosphere was studied by means of hot air oven drying (sample 7) and using of a desiccator (sample 9) for 5 and 216 hours, respectively (note that drying times are not equal). It was found that samples exhibit mean micropore volumes of 0.093 and $0.106 \mathrm{~cm}^{3} \mathrm{~g}^{-1}$, respectively and mean micropore surfaces of 247 and $278 \mathrm{~m}^{2} \mathrm{~g}^{-1}$, respectively. In such a way pre-treated samples also have lower characteristic energy values (9.10 and $8.84 \mathrm{~kJ} \mathrm{~mol}^{-1}$, respectively) and higher values of the $r_{\text {mode }}(0.68$ and $0.69 \mathrm{~nm}$, respectively). These procedures were carried out under ambient pressure conditions in the presence of air. Therefore, the lowtemperature oxidation of the coal samples likely occurred. The residual contents of the moisture correspond with the 1.4 and $2.1 \mathrm{wt}$ \% for hot air oven drying (sample 7) and desiccator drying (sample 9), respectively. Using of these methods cannot be expected to result in a completely dry state of the subbituminous coal.

\subsection{Effect of drying time}

The influence of the pre-treating time was mainly studied according to the vacuum pumping method. Samples 4, 1 and 5 were dried for 2, 5 and 8 hours, respectively at temperature $60^{\circ} \mathrm{C}$. It can be seen (table 4) that samples 4 and 5 exhibits basically the same microporous parameters $\left(S_{m i} \sim 300 \mathrm{~m}^{2} \mathrm{~g}^{-1}, V_{m i} \sim\right.$ $\left.0.11 \mathrm{~cm}^{3} \mathrm{~g}^{-1}, r_{\text {mode }}=0.67 \mathrm{~nm}\right)$ despite the difference in residual moisture content.

From this one can conclude that two hours is sufficient time (at $60^{\circ} \mathrm{C}$ ) for the vacuum pre-treatment method for this subbituminous coal. Incomparably longer drying time is probably needed in the case of lyophilisation (70 hours) and the desiccator drying procedure (216 hours). On the other hand, kinetic data from these procedures were not collected. Further experiments have to be realized for in-depth examination of this issue. 


\section{Conclusions}

Experimental adsorption data were successfully fitted by the modified DR model. The micropore parameters obtained from this fitting show the following findings. It was found that the drying method of the subbituminous coal influences its final state.

(i) It was found that samples that were not exposed to oxygen during drying have better micropore characteristics, likely due to the lower contents of the residual moisture $(\leq 0.4 \mathrm{wt}$. \%). However, the reduction of the textural parameters of non-oxidizing atmosphere is likely related with filling of micropores by residual moisture, which is higher for a hot air dried sample (1.4 wt. \%).

(ii) It was found that there are not significant differences according to microporous textural parameters (statistically evaluated in such way) with respect to a comparison of the minimal and maximal residual water content values. On the other hand, the residual moisture content may be responsible for the shifting of the mode of the micropores radii to the higher values with respect to air dried samples of the coal. The effect of the drying at elevated temperatures under vacuum was not proved, nor was a significant effect of temperature pretreatment regardless of the used method. However, $60^{\circ} \mathrm{C}$ is sufficient temperature for vacuum drying.

(iii) Monitoring of the effect of the pre-treatment time proved that 2 hours is sufficient time for a clean surface using vacuum pumping at $60^{\circ} \mathrm{C}$. The obtained microporous parameters of samples dried for 2 and 8 hours were negligible (even despite the difference in residual moisture contents of these samples).

\section{Acknowledgements}

The article has been drawn up in connection with the project of the Institute of Environmental Technologies, reg. No. CZ.1.05/2.1.00/03.0100 supported by the Research and Development for Innovations Operational Programme financed by Structural Funds of the European Union and from the means of the state budget of the Czech Republic. The paper was also supported by SGS, reg. No. SGS02/PřF/2013.

\section{References}

[1] Yu, J., Tahmasebi, A., Han, Y., Yin, F., Li, X., A review on water in low rank coals: The existence, interaction with coal structure and effects on coal utilization. Fuel Processing Technology, 106, pp. 9-20, 2013.

[2] Taraba, B., Nizkoteplotni oxidace a samovznécování uhelné hmoty, Ostravská univerzita: Ostrava, 2003 (in Czech).

[3] Day, S., Sakurovs, R., Weir, S., Supercritical gas sorption on moist coals. International Journal of Coal Geology, 74, pp. 203-214, 2008. 
[4] Siemons, N., Busch, A., Measurement and interpretation of supercritical $\mathrm{CO}_{2}$ sorption on various coals. International Journal of Coal Geology, 69, pp. 229-242, 2007.

[5] Clarkson, C.R., Bustin, R.M., Binary gas adsorption/desorption isotherms: effect of moisture and coal composition upon carbon dioxide selectivity over methane. International Journal of Coal Geology, 42, pp. 241-271, 2000.

[6] Švábová, M., Weishauptová, Z., Přibyl, O., The effect of moisture on the sorption process of $\mathrm{CO}_{2}$ on coal. Fuel, 92, pp. 187-196, 2012.

[7] Brennan, J.K., Thomson, K.T., Gubbins, K.E., Adsorption of water in activated carbons: effect of pore blocking and connectivity. Langmuir, 18, 5438-5447, 2002.

[8] Pisupati, S.V., Scaroni, A.W., Effects of natural weathering and lowtemperature oxidation on some aspects of the combustion behaviour of bituminous coals. Fuel, 72, pp. 779-785, 1993.

[9] Fei, Y, Artanto, Y, Giroux, L., Marshall, M., Jackson, W.R., MacPhee, J.A., Charland, J-P., Chaffee, A.L., Allardice, D.J., Comparison of some physico-chemical properties of Victorian lignite dewatered under nonevaporative conditions. Fuel, 85, pp. 1987-1991, 2006.

[10] Bergins, Ch., Hulston, J., Strauss, K., Chaffee, A.L., Mechanical/thermal dewatering of lignite. Part 3: Physical properties and pore structure of MTE product coals. Fuel, 86, pp. 3-16, 2007.

[11] Medek, J., Possibility of micropore analysis of coal and coke from the carbon dioxide isotherm. Fuel, 56, pp.131-133, 1977.

[12] Medek, J., Weishauptová, Z., Vliv mikropórovitosti koksů na jejich vlastnosti, 1. část - Mikropórovitost jako charakteristická složka porézní struktury koksů. Uhlí, 35, pp. 170-174, 1987 (in Czech).

[13] Lowell, S., Shields, J.E., Thomas, M.A., Thommes, M., Characterisation of porous solids and powders: Surface area, pore size and density, Springer: Dordrecht, pp. 29-33, 2004.

[14] Medek, J., Weishauptová, Z., The microporous phase of carbonaceous substances and its fractal dimension. Fuel, 79, pp. 1621-1626, 2000.

[15] Taraba, B. Personal communication, 8 October 2012, Professor at the Department of Chemistry, University of Ostrava.

[16] Evans, D.G., The brown-coal/water system: Part 4. Shrinkage on drying. Fuel, 52, pp. 186-190, 1973.

[17] Deevi, S.C., Suuberg, E.M., Physical changes accompanying drying of western US lignites. Fuel, 66, pp. 454-460, 1987. 